\title{
PENGGUNAAN DONGENG DALAM PEMBENTUKAN KARAKTER PADA ANAK DI TK DHARMA PRAJA4.2 DONGENG YANG DIBERIKAN PADA ANAK DI TAMAN KANAK-KANAK (TK) DHARMA PRAJA
}

Oleh :

Ni Made Anggreni

\begin{abstract}
ABSTRAK
Pendidikan masa awal kanak-kanak ditantang untuk memperkenalkan anak-anak kepada dunia untuk masa depan mereka, suatu dunia yang akan terus meningkat menjadi multikultural dan banyak suku. Metode dongeng adalah salah satu alat yang kuat untuk meningkatkan suatu pemahaman diri dan orang lain

Kekuatan utama dari strategi dongeng adalah menghubungkan rangsangan melalui penggambaran karakter. Dongeng memiliki potensi untuk memperkuat imajinasi, memanusiakan individu, meningkatkan empeti dan pemahaman, memperkuat nilai dan etika, serta merangsang proses pemikiran kritis dan kreatif. Mendongeng dapat dijadikan sebagai media pembentukan karakter pada anak usia dini. Dengan mendongeng akan memberikan pengalaman belajar bagi anak usia dini. Metode mendongeng dapat memberikan sejumlah pengalaman yang dibutuhkan dalam perkembangan kejiwaan anak. Dengan dongeng akan memberikan wadah bagi anak untuk belajar berbagai emosi dan perasaan serta belajar nilai-nilai karakter. Anak akan belajar pada pengalaman-pengalaman sang tokoh dalam dongeng, setelah itu memilah mana yang dapat dijadikan panutan olehnya sehingga membentuknya menjadi sebuah karakter yang baik.

TK Dharma praja merupakan salah satu TK yang masih menggunakan dongeng sebagai salah satu metode pembelajarannya. Walaupun TK ini berada di Kota Denpasar. Kota Denpasar merupakan kota yang dihuni oleh masyarakat multi etnis dan agama, akan tetapi para guru di TK ini tetap mempertahankan tradisi dongeng ini sebagai upaya dalam pembentukan karakter anak.
\end{abstract}

Kata Kunci: Dongeng, Pembentukan Karakter

Anak usia prasekolah dipandang sebagai individu yang baru mulai mengenal dunia.Anak belum memahami tatakrama, sopan santun, aturan, norma, etika, dan berbagai hal yang terkait dengan kehidupan dunia. Usia prasekolah merupakan masa bagi seorang anak untuk belajar berkomonikasi dengan orang lain serta memahaminya. Oleh karena itu seorang anak perlu dibimbing dan diberi stimulasi agar mampu memahami berbagai hal tentang kehidupan dunia dan segala isinya.

Pemberian stimulasi pada anak selama proses pengembangan kepribadian menjadi sangat penting. Stimulasi identik dengan pemberian rangsangan yang berasal dari lingkungan di sekitar anak guna lebih mengoptimalkan aspek perkembangan anak. Fittro (Mukti dan Hwa dalam Nur Ahyani: 
2010) menyatakan bahwa anak-anak mengembangkan moralitas perlahan dan bertahap. Setiap tahap membawa anak lebih dekat dengan pembangunan moral dewasa. Fitto juga mencatat bahwa salah satu cara yang efektif untuk membantu anak-anak merubah moralnya menjadi positif adalah mengajar perilaku moral dengan contoh yang positif. Mendongeng atau membacakan dongeng merupakan salah satu cara untuk menghubungkan mereka dengan sebuah prinsip ataunilai.

Pendidikan masa awal kanak-kanak ditantang untuk memperkenalkan anak-anak kepada dunia untuk masa depan mereka, suatu dunia yang akan terus meningkat menjadi multikultural dan banyak suku. Metode dongeng adalah salah satu alat yang kuat untuk meningkatkan suatu pemahaman diri dan orang lain (Lenox dalam Nur Ahyani, 2010).

Adapun dongeng-dongeng yang diberikan pada anak-anak TK di Dharma Praja adalah a) Persahabatan Tiga Ekor Binatang, b) Anak Domba Pengarang, c) Aku Tidak Mau Mandi, d) Bimbim Si Jujur, e) Kera Yang Nakal, f) Kisah Sebutir Biji, g) Kancil Yang Cerdik, h) Puteri Pecinta Tanaman, i) Hadiah Dari Ayah, danj) Kancil dan Kerbau.

\section{Persahabatan Tiga Ekor Binatang}

Gajah, Kancil dan Ular tiga ekor binatang yang saling bersahabat dan saling membantu. Karena hari sudah sore mereka pulang ke rumah masing-masing. Ditengah perjalanan $\mathrm{Si}$ Kancil terpeleset ke lubang perangkap yang dibuat oleh pemburu. Si Kanci minta tolong, kemudian didengar oleh Gajah. Gajah menolong Kancil untuk keluar dari perangkap tersebut. Si Kancil mengucapkan terima kasih kepada Si Gajah yang telah menolongnya. Karena kelelahan akhirnya Si Gajah berhenti untuk beristirahat. Ketika pemburu sedang berjalan, mereka melihat Gajah yang sedang istirahat. Bersiap-siaplah pemburu itu menembaknya namun pemburu kesakitan. Ternyata kaki pemburu digigit ular, kemudian mereka lari tunggang langgang. Si Gajah terkejut, ia pun ikut lari. Akhirnya Si Gajah bertemu Si Ular yang telah menolongnya. Kemudian mereka pulang bersama-sama.

\section{Anak Domba Pengarang}

Diceritakan seekor domba baru berumur empat jam. Domba bisa melihat dan mendengar, tetapi kakinya masih lemah. Domba minum susu dari ibunya. Bulu domba yang tebal membuatnya tetap hangat saat tidur. Domba sudah berumur satu hari, kakinya semakin kuat. Domba selalu berada di dekat ibunya, dan mengembik dengan keras bila ibunya menjauh. Domba hanya bisa berdiri sebentar, kemudian jatuh lagi. Umur domba sekarang empat minggu. Bulunya yang lebat tumbuh semakin tebal. Sekarang domba berumur delapan minggu. Aku senang berkejar-kejaran dengan saudaraku dan domba-domba lainnya di lapangan.Aku sekarang sudah berumur sepuluh minggu. Aku senang memakan rumput hijau yang segar. Aku dan saudaraku sering makan rumput bersama. Aku berumur dua belas 
minggu. Buluku semakin panjang. Kami hampir sebesar ibu kami. Sebentar lagi kami akan dewasa.

\section{Aku Tidak Mau Mandi}

Diceritakan Harimau cilik sangat bermain saat bermain dia kotor. Ibu harimau kemudian menyuruh harimau mandi, tetapi harimau tidak mau mandi dan berlari ke hutan. Harimau kemudian bermain dengan si Monyet. Mereka memanjat pohon dan main ayunan dengan tanaman rambat. Harimau jatuh dan kainya kotor. Ibu monyet datang untuk mengajak moyet dan harimau mandi. Tapi harimau tidak mau mandi dan berlari kesemak-semak. Harimau kemudian bermain dengan beruang. Mereka berputar dan beuling di semak-semak dan mencari stroberi. Air stroberi mengotori selurh muka harimau. Setelah itu Harimau mengajak burung merak untuk bermain. Tetapi si burung merak tidak mau bermain dengan harimau karena dia kotor sekali. Harimau merasa sakit hati kemudian pergi hingga sampai di sungai. Bermain dengan teman-teman membuatnya haus dan dia berhenti untuk minum. Ketika ia melihat sebuah bayangan di air dan dia terjebur ke sungai. Ketika sudah bersih, harimau naik kembali ke pinggir untuk mengagumi banyangannya. Ada macan tutul lewat dan memanggil harimau untuk bermain. Tapi harimau tidak mau karena melihat macan tutul kotor lalu menyuruh macan tutul mandi. Dengan bernafas kencang dan cepat Harimau berlari pulang ke rumah.

\section{Bimbim Si Jujur}

Pada setiap pagi Bombom pergi ke sekolah, dia diantar oleh adiknya Bimbim yang masih kecil. Bimbim suka sekali bermain jika dia sendiri, dia akan bermain lompat-lompatan di halaman rumahnya. Suatu hari Bimbim pergi ke dapur. Diatas meja ada dua wortel segar. Bimbim memakan satu buah, karena belum kenyang diambilnyalagi satu. Bimbim kemudian melompat dan bersembunyi di bawah meja. Bombom sudah pulang dari sekolah, lalu pergi ke dapur. Di atas meja hanya tinggal remahremah wortel. Ibu kelinci marah melihat hal tersebut dan memberi Bombom hukuman tidak boleh bermain dan tidak mendapat wortel lagi. Bimbim masih di bawah meja, dia menutup matanya. Dia merasa bersalah kepada Bombom, Bombom tidak bersalah. Kemudian Bimbim keluar dari persembunyiannya dan mengakui bahwa bukan Bombom yang menghabiskan wortel tetapi Bombom yang memakan.

\section{Kera Yang Nakal}

Diceritakan pada sebuah hutan hidup seekor kera yang nakal sekali. Ia senang mengganggu dan menipu teman-temannya. Timbul akal liciknya, ketika kelinci sedang sibuk memetik wortel ditukarnya tas kelinci dengan sebuah bungkusan dan kelinci membuka bungkusan itu. Ternyata berisi sekelompok lebah dkelinci lari ketakutan. Ketika dilihatnya $\mathrm{Bu}$ Ayam membawa keranjang jagung, timbul lagi niat jeleknya lagi untuk merampas jagung 
itu. Dia berpura-pura membantu Bu Ayam membawa keranjang lalu mengejutkan $\mathrm{Bu}$ Ayam bahwa ada ulah besar, karena terkejut Bu Ayam lari ketakutan dan kera mendapatka jagung-jagung itu. Suatu hari kera bertemu Landak yang membawa apel. Muncul memiliki apel itu dengan membilang bahwa apel yang dibawanya beracun. Landak tahu bahwa kera ingin menipunya. Landak pun menyarankan kera untuk memeriksa pohonnya dan mereka pergi menuju ke pohon apel itu. Monyet berlagak memeriksa apel-apel itu. Tetapi dia malah asik menikmati apel di atas pohon. Tibatiba landak berkata bahwa ada ular, karena terkejut kera jatuh. Sedangkan landak telah siap menegakkan durinya lalu Kera jatuh menimpa tubuh Landak. Kera menjerit dan menangis kesakitan .

\section{Kisah Sebutir Biji}

Kisah buah manga banyak orang yang suka, manga tidak setiap waktu ada. Tempat mangga tinggi diujung ranting, bila masak mangga berwarna kuning. Suatu hari pemilik kebun dan pembantunya memetik mangga. Setelah itu kulit dan biji mangga dibuang ke tempat sampah. Seorang anak membawa biji mangga dan menanam. Kini biji mangga mulai tumbuh, tumbuhan itu disiram setiap hari aku disiram. Makin lama pohon mangga makin besar. Sekarang pohon mangga telah dewasa kini musim berbuah tiba buah mangga makin lama makin besar. Sekarang buah manga makin banyak dan masak, anak-anak pun ingin memetik dan merasakan manisnya buah mangga.

\section{Kancil Yang Cerdik}

Diceritakan ada kancil yang sangat cerdik. Suatu hari si kancil melihat Harimau dan Singa sedang berkelahi. Si kancil berusaha untuk melerai, apadaya kedua binatang itu tidak mau berhenti bertengkar. Keduanya bersikeras mengaku diri paling kuat dan berkuasa di hutan. Harimau mengaku dirinya paling kuat dan menjadi raja hutan. Sedangkan singa mengaku juga dirinya paling kuat dan penguasa.Akhirnya si kancil berpikir, bagaimana carany menundukan kesombongan mereka. Dengan menunjukkan sarang tawon di atas pohon. Ia mengatakan bahwa, jika kalian kuat coba kalian pukul benda bulat itu. Dengan semangat kedua binatang itu mendekati dan memukuli sarang tersebut.Akhirnya semua tawon keluar, karena rumahnya ancur dan menggigit mereka. Akhirnya mereka menyadari bahwa tidak boleh sombong, karena masih ada yang lebih kuat dari merekaberdua.

\section{Puteri Pencinta Tanaman}

Diceritakan anak yang Puteri sangat menyayangi tanaman. Tamanan yang dimiliki ialah “daun ajaib”, tanam bunga aster, kembang Desember. Tanaman sangat berguna bagi kehidupan manusia. Karena dalam tanaman tersedia gas oksigen yang diperlukan bagi pernafasan kita. Puteri, ayah, ibu dan kakaknya selalu membuang sampah pada tempatnya. Mereka menyadari sampah merupakan sumber penyakit. Hari itu Dina dan Ayu berkunjung berkunjung kerumah Puteri. Mereka akan menenggokTina, kawan sekelasnya yang sudah beberapa hari tidak sekolah. Di rumah Tina 
tidak ada tanaman, sehingga membuat Puteri, Dina danAyu heran. Kemudian memberi saran agar Tina nanti menanam tumbuhan. Karena tumbuhan merupakan rahmat dari Tuhan. Setelah sembuh Tina pun menanam tumbuhan yang diberikan Puteri. Teras rumah yang semulanya gersang sekarang menjadi sejuk. Ayah dan Ibu Tina yang semula tidak memperdulikan tanaman akhirnya mulai menyenangi tanaman serta mereka menambah koleksi tanaman di teras.

\section{Hadiah Dari Ayah}

Dikisahkan dodi hari ini ulang tahun, dodi mengundang teman-temannya. Teman-teman dodi datang dengan berpakaian rapi. Dodi saat itu berjanji akan menurut perintah ayah dan ibu. Setelah selesai menyanyikan lagu uang tahun dodi memotong kue untuk dimakan bersama. Ayah memberikan nasehat kepada dodi agar patuh kepada orang tua dan guru. Setiap hari dodi harus bangun pagi, mandi, dan gosok gigi, serta rajin berdoa. Dodi mendapatkan hadiah sepeda roda tiga dari ayah. Karena sudah siang teman-teman dodi berpamitan untuk pulang. Ayah berpesan, jika dodi bermain sepeda jangan di jalan raya supaya tidak kena bahaya

\section{Kancil Dan Kerbau}

Diceritakan kerbau bertemu kancil, dan kanci berpesan hati-hatilah bila bertemu harimau dan buaya karena punggung mu yang lunak menjadi incaran mereka. Kerbau merenungkan pesan dari kancil. Suatu hari buaya memanggil kerbau, untuk minta tolong agar mengangkat pohon yang menimpa istri buaya. Dengan waspada kerbau membantu buaya, sebelumnya kerbau berdoa untuk mohon kekuatan kepada Tuhan. Kerbau memang dikenal hewan yang baik di seluruh hutan. Kerbau juga pernah menolong anak gembala yang akan dimangsa oleh harimau. Sejak saat itu anak gembala dan kerbau menjadi sahabat. Si kancil pun tak berhasil mengadu domba antara kerbau, buaya dan harimau.

Dongeng diceritakan pada anak dalam setiap kali pembelajaran. Guru bercerita dengan anak dengan membacakan dongeng atau cerita. Anak di minta untuk mendengarkannya dengan baik. Setelah mengakhiri cerita guru memberikan pertanyaan kepada anak-anak. Pertanyaan diberikan secara lisan. Guru meminta anak untuk menceritakan kembali dongeng itu. Kemudian anak yang lain juga diminta untuk menyebutkan tokoh-tokohyang ada dalam dongeng. Guru juga meminta pada anak untuk mengidentifikasi mana tokoh yang memiliki prilaku yang baik dan mana yang tidak. Kemudian guru memberikan umpan balik yaitu mana sehrusnya prilaku yang dapat ditiru oleh anak dan mana prilaku yang tidak layak untuk ditiru.Guru juga memberikan penjelasan kepada anak apa akibat dari perbuatan yang tidak baik dan apa akibatnya jika melakukan perbuatan yang baik (Purnawati, tanggal 29 mei 2015).

Selain dengan cara lisan guru di TKDarma Praja juga memberikan cerita atau dongeng pada anak dengan menggunakan alat peraga. Adapun alat peraga yang dimaksud adalah boneka tangan. Hal ini dilakukan untuk menarik minat dan motivasi anak untuk mendengarkan cerita atau dongeng, karena terkadang anak 
kurang perhatian pada cerita yang disampaikan oleh gurunya. Dengan menggunakan media ini anak jadi menarik mendengarkan cerita yang disampaikan oleh guru sehingga pesan yang ada dalam cerita itu dapat disimak dengan baik oleh siswa (wawancara tanggal 29 Mei 2015) adapun cara penggunaan boneka tangan yang dimaksudkan disini adalah satu tangan ada boneka sebagai tokoh si Kancil dan tangan yang lain ada boneka sebagai tokoh Beruang. Sekenario dalam cerita si Kancil dan Beruang. Skenario pembelajarannya hampir sama dengan mendongeng atau bercerita dengan membacakan cerita, hanya saja kegiatan ini dilakukan pada hari jumat dan sabtu. Biasanya guru sebelum memulai bercerita mengajak siswa untuk berbaris yang dilanjutkan dengan bernyanyi sehingga tercipta suasana riang gembira. Siswa tampak antusias dalam mendengarkan cerita guru yang ditunjukkan dengan siswa berusaha membantu guru dalam memilih boneka yang sesuai dengan tokoh cerita yang akan diceritakan oleh guru, Pada saat itu guru bertanya kepada anak "Siapa yang bisa membantu Bu guru untuk menunjukkan boneka sesuai cerita yang ibu ceritakan?" anak-anak menjawab dengan semangat "Saya bu guru!" Anak yang paling semangat dan paling tinggi angkat tangannyalah yang mendapat bagian, seperti yang terlihat dalam gambar.

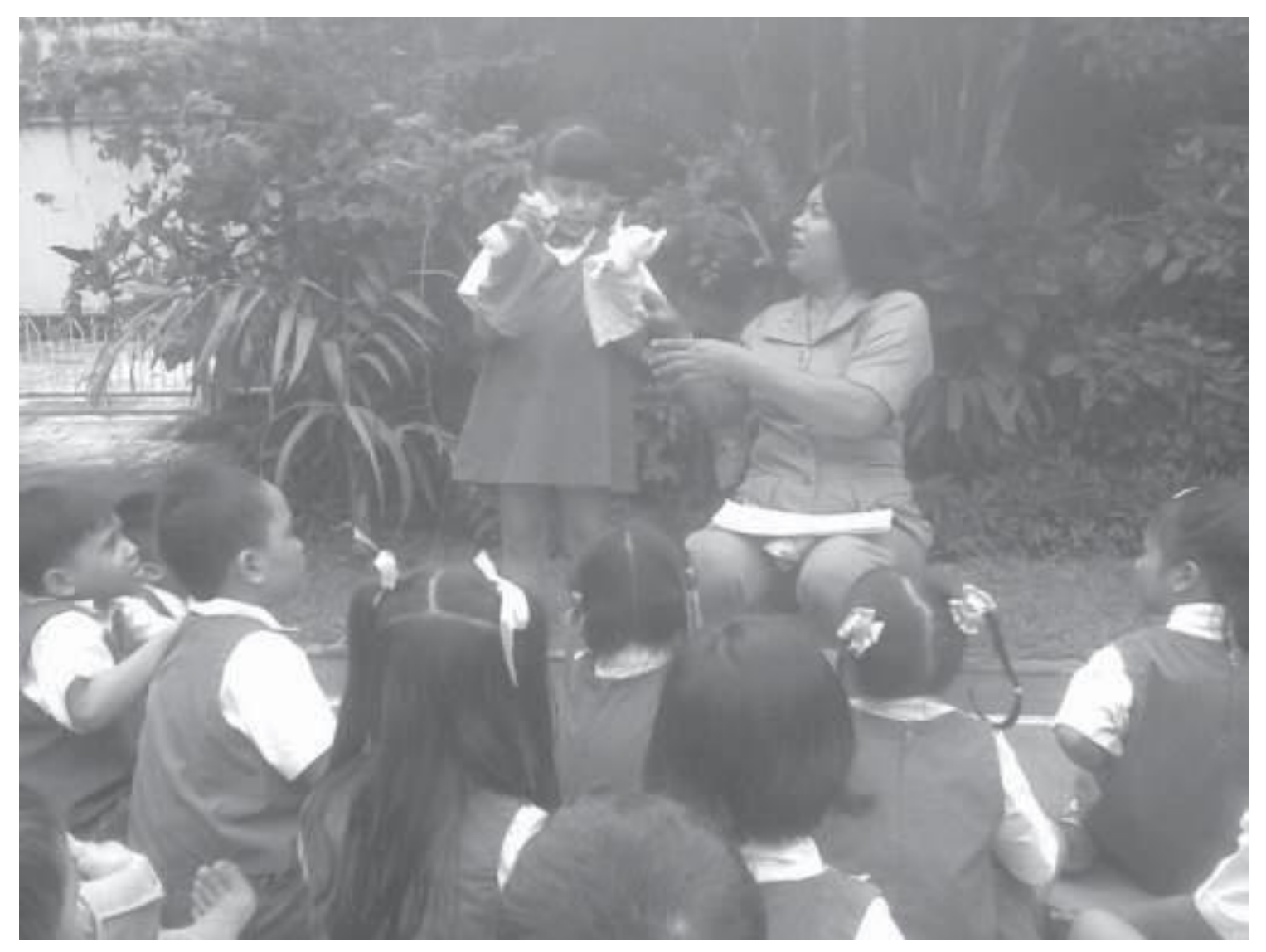

Kegiatan Bercerita di Luar Kelas

(Dokumentasi: TK Dharma Praja, 2015)

PENGGUNAAN DONGENG DALAM PEMBENTUKAN KARAKTER PADA ANAK DI TK DHARMA PRAJA 4.2 DONGENG YANG DIBERIKAN PADA ANAK..... 
Selanjutnya guru meminta anak menyimak cerita agar nanti bisa menjawab pertanyaan guru. Dari cerita tersebut, anak diminta untuk menyebutkan nama-nama tokoh dan menceritakan kembali secara singkat isi cerita (obsevasi tgl 8 Mei 2015). Cara menumbuhkan karakter yang baik pada diri anak didik adalah dengan membangun kecerdasan moral.

Kecerdasan moral adalah keyakinan etika yang kuat dan bertindak berdasarkan keyakinan tersebut, sehingga orang bersikap benar dan terhormat (Zubaedi,2011:55). Dalam ceritacerita yang diceritakan guru pada anak TK DarmaPraja mengandung nilai nilai yang sarat

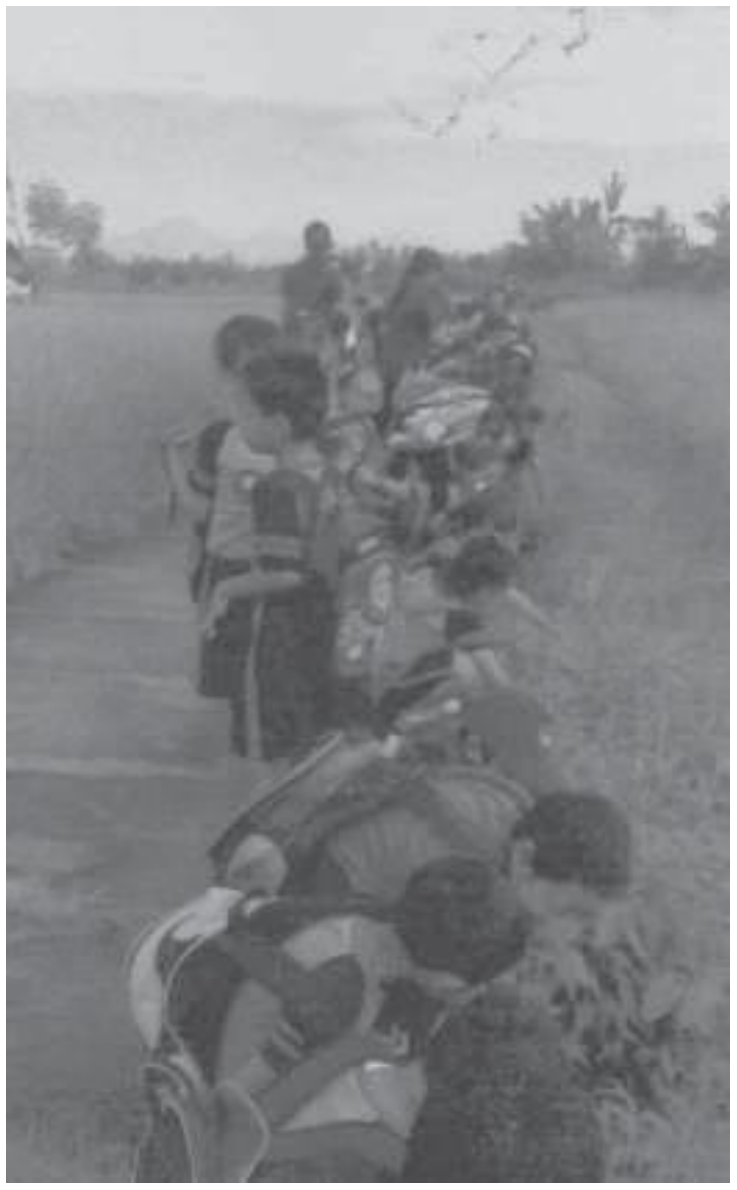

Guru Sedang Bercerita Mencintai Alam (Dokumentasi: TK Dharma Praja, 2015) akan pesan pesan moral tersebut. Kecerdasan yang sangat penting ini mencakup karakterkarakter utama, seperti kemampuan untuk memahami penderitaan orang lain dan tidak bertindak dan menunda pemuasan, mendengarkan dari berbgai pihak sebelum memberikan penilaian, menerima dan memberikan penilaian, menerima dan menghargai perbedaan, bisa memahami pilihan yang tidak etis, dapat berempati, memperjuangkan keadilan, dan menunjukkan kasih sayang dan rasa hormat terhadap orang lain.

\section{DAFTAR PUSTAKA}

Amri, Sofan., dkk. 2011. Implementasi Pendidikan Karakter Kayum Dalam Pembelajaran. Jakarta: PT Prestasi Pustakaraya.

Anandakusuma, Sri Reshi. Kamus Bahasa Bali.Cv Kayumas Agung.

Ani. 1991. Hadiah Dari Ayah. Solo: Tiga Serangkai.

Astini, Ni Wayan. 2010. Analisis Bentuk, Fungsi dan Makna Satua I Siap Selem Sebagai Media Pendidikan Anak di Desa Sidan. Tugas Akhir (tidak diterbitkan). Jurusan Pendidikan Bahasa Bali. IHDNDenpasar.

Balitbang, Departemen Pendidikan Nasional, III. (2010). Jakarta

Bandura, A. 1977. Sosial Learning Theory. Englewood Cliffs, N.J.: Prentice Hall. 
Basir, Lies. 1990. Kisah Sebutir Biji. Klaten: PT. Intan Pariwara.

Dahar, Ratna Wilis. 1996. Teori-Teori Belajar.

Jakarta: Erlangga.

Dewi, Putu Ratna Sari. 2012. Eksistensi Gending Rare Dalam Menanamkan Nilai Budi Pekerti di TK Negeri 1 Kerambitan. Tugas Akhir (tidak diterbitkan). Jurusan Pendidikan Bahasa Bali. IHDNDenpasar.

Dimas P W. 2009. Kancil Yang Cerdik.

Malang: Mahameru Pustaka.

Djaali, H. 2012. Psikologi Pendidikan.

Jakarta: PT Bumi Aksara.

Eagleton, Terry. 2007. Teori Sastra.

Yogyakarta: Jalasutra. 
Hatmi, Tri. 2000. Persahabatan Tiga Ekor Binatang. Jakarta: Departemen Pendidikan Nasional.

Indarwati, Lucia. 1993. Bimbim Si Jujur.

Yogyakarta: Kanisius.

Keriana, I Ketut. 2010. Pupulan Satua Bali.

Bali: Gandapura.

Kesuma, Tri Mastoyo Jati. 2007. Pengantar Metode Penelitian Bahasa. Yogyakarta: Carasvatibooks.

Mastoyo. 2001. Metodologi Peneliian Bidang Sosial. Jakarta: Airlangga.

Muslich, Masnur. 2011. Pendidikan Karakter.

Jakarta Bumi Aksar 